\title{
The association between monthly social assistance disbursement days and emergency department visits for trauma, mental health, and substance use
}

\author{
Seraph L. Bao ${ }^{1} \cdot$ Shannon Erdelyi ${ }^{2} \cdot$ Herbert Chan $^{2,3} \cdot$ Leona K. Shum ${ }^{2} \cdot$ John A. Staples ${ }^{3,4} \cdot$ Jeffrey R. Brubacher ${ }^{2,3}$ (D)
}

Received: 2 November 2020 / Accepted: 2 March 2021 / Published online: 1 April 2021

( ) The Author(s), under exclusive licence to Canadian Association of Emergency Physicians (CAEP)/ Association Canadienne de Médecine d'Urgence (ACMU) 2021

\begin{abstract}
Objective Social assistance helps fulfill the basic needs of low-income individuals. In British Columbia, social assistance is issued on the third or fourth Wednesday of every month. However, this sudden influx of resources may have negative health consequences. We investigated social assistance timing and emergency department (ED) visits related to trauma, mental health, and substance use.

Methods We conducted a retrospective multi-centre observational study using 12 years of regional ED data from Vancouver, British Columbia (2008-2020). Each cheque week (the week following social assistance disbursement) was matched to a single control week ( 2 weeks prior to cheque week). We compared the number of ED visits for trauma, mental health, and substance use during cheque weeks versus control weeks.

Results There were 253,360 visits during all weeks of interest. Cheque week was associated with significantly more ED visits for mental health and substance-related presentations (RR 1.07, 95\% CI 1.03-1.11, $p=0.0006$ ). These visits increased significantly for both males and females and for adults aged 17-64 years. Mental health and substance-related visits increased on the day of cheque disbursement (Wednesday) and the 4 days following (Thursday-Sunday). Trauma-related ED visits were elevated on the day of cheque disbursement, but not during other days of the week.

Conclusions Social assistance disbursement is followed by an increase in mental health and substance-related ED presentations and may be associated with an increase in trauma presentations on the day of cheque disbursement. These findings support calls for clinical and policy-level changes and support to reduce cheque day-associated harm.
\end{abstract}

Keywords Income assistance $\cdot$ Emergency department visits $\cdot$ Mental health $\cdot$ Substance use $\cdot$ Trauma

\section{Résumé}

Objectif L'aide sociale permet de répondre aux besoins fondamentaux des personnes à faible revenu. En Colombie-Britannique, l'aide sociale est versée le troisième ou le quatrième mercredi de chaque mois. Cependant, cet afflux soudain de ressources peut avoir des conséquences négatives sur la santé. Nous avons étudié le calendrier de l'aide sociale et les visites aux urgences liées aux traumatismes, à la santé mentale et à la toxicomanie.

Jeffrey R. Brubacher

Jeff.Brubacher@ubc.ca

1 Faculty of Science, University of British Columbia,

Vancouver, BC, Canada

2 Department of Emergency Medicine, University of British Columbia, Vancouver, BC, Canada

3 Centre for Clinical Epidemiology and Evaluation (C2E2), Vancouver, BC, Canada

4 Department of Medicine, University of British Columbia, Vancouver, BC, Canada 
Méthodes Nous avons mené une étude d'observation rétrospective multicentrique en utilisant 12 années de données sur les urgences régionales de Vancouver, en Colombie-Britannique (2008-2020). Chaque semaine de chèque (la semaine suivant le versement de l'aide sociale) a été appariée à une seule semaine de contrôle (deux semaines avant la semaine de chèque). Nous avons comparé le nombre de visites aux urgences pour traumatisme, santé mentale et toxicomanie pendant les semaines de chèque et les semaines de contrôle.

Résultats Il y a eu 253360 visites pendant toutes les semaines d'intérêt. La semaine des chèques a été associée à un nombre significativement plus élevé de visites aux urgences pour des présentations liées à la santé mentale et à la toxicomanie (RR 1,07, IC $95 \%$ 1,03-1,11, p = 0,0006). Ces visites ont augmenté considérablement chez les hommes et les femmes et chez les adultes de 17 à 64 ans. Les visites liées à la santé mentale et aux substances ont augmenté le jour du versement du chèque (mercredi) et les quatre jours suivants (jeudi - dimanche). Les visites aux urgences liées à un traumatisme étaient plus nombreuses le jour de la remise du chèque, mais pas les autres jours de la semaine.

Conclusions Le versement de l'aide sociale est suivi d'une augmentation des présentations aux urgences liées à la santé mentale et à la toxicomanie et peut être associé à une augmentation des présentations de traumatismes le jour du versement du chèque. Ces résultats appuient les appels à des changements et à un soutien au niveau clinique et politique afin de réduire les préjudices associés au jour du chèque.

\section{Clinician's capsule}

What is known about the topic?

The days following social assistance disbursement are frequently associated with substance use-related harms and an increased burden on health systems.

What did this study ask?

What is the association between cheque disbursement and Emergency Department presentations for trauma, mental health, and substance use?

\section{What did this study find?}

Mental health and substance-related Emergency Department visits increased significantly during cheque week, while trauma-related visits increased on cheque day only.

Why does this study matter to clinicians?

Anticipating increases in Emergency Department use can improve resource allocation, preparation, and policy, both within EDs and in the community.

\section{Introduction}

Income assistance, or social assistance, is a form of government-issued support for low-income individuals. These programs reduce poverty [1]. In British Columbia (BC) social assistance is paid out on the third or fourth Wednesday of every month [2], commonly referred to as "cheque day" or "Welfare Wednesday". However, previous literature suggests that negative consequences associated with increased resources may also follow social assistance disbursement [3]. The monthly surge in adverse health events around cheque day has become known as the "cheque effect" [3].

Cheque distribution days have been associated with increased hospital admissions and use of ambulance services, jails, and alcohol receiving centres [4]. Research has also demonstrated the cheque effect in $\mathrm{BC}$ in public service use (e.g. police apprehensions, 911 or ambulance call volume, and sobering unit or jail time) [4]. However, in community forums and consultation sessions, there was anecdotal evidence of a higher number of assaults, altercations, violent crime, and violence against police officers following cheque day [5]. Despite this, the impact of social assistance disbursement timing on all-cause emergency health service use and trauma-specific hospital visits has not been examined.

In this study, we examine the association between cheque disbursement and the number of ED visits related to trauma, mental illness or substance use. These findings can be used to guide allocation of resources (e.g., staffing levels) in EDs and inform policy-level changes to reduce harms related to disbursement.

\section{Methods}

\section{Study design and setting}

We conducted a retrospective observational study using ED database information from three Greater Vancouver hospitals: Vancouver General Hospital (VGH), University of British Columbia Hospital (UBCH), and Richmond General Hospital (RGH). Data were analyzed from January 1st, 2008 until April 30th, 2020. ED visits were categorized by standardized Canadian Emergency Department Information System (CEDIS) presenting complaints [6]. Two weeks of unavailable data in 2019 (August 9-15 and November 1-7) were excluded. This study was approved by the University of British Columbia Research Ethics Board. 


\section{Outcomes}

Visits were categorized a priori according to CEDIS presenting complaint into (1) trauma-associated visits, and (2) mental health and substance-related visits. Trauma-related ED visits were also identified by a mechanism of trauma flag, which is added to the ED visit record of all injured patients at participating hospitals. Cheque-issue dates were obtained from the BC Ministry of Social Development and Poverty Reduction. Each cheque week (12:00 PM on the Wednesday of cheque disbursement until 11:59 AM the following Tuesday) was matched to one control week (2 weeks prior). For each analysis, the number of ED visits of interest during cheque weeks were compared to those during control weeks.

\section{Analysis}

Poisson regression or negative binomial regression model (in the event of overdispersion) was used to model the count of weekly ED visits. Models included a coefficient for week type (cheque or control). Model fit was examined using Chisquare goodness of fit tests on the residual deviance. In most cases, these tests indicated adequate fit for negative binomial models, with the exception of few annual subgroup analyses where a Poisson model was sufficient. Model coefficients were used to compute the relative risk (RR), and corresponding $95 \%$ confidence intervals (CIs), of ED visits on cheque versus control weeks. The number of excess ED visits was obtained from a nonparametric bootstrap confidence interval using the adjusted bootstrap percentile method. The bootstrap statistic was generated from coefficient estimates in the negative binomial regression model. All statistical tests were two-sided with a significance level of 0.05. Analyses were performed using R v 3.5.1 statistical software [7].

\section{Results}

Total trauma visits by trauma flag were 84,055 in cheque weeks and 84,236 in control weeks $(\mathrm{RR}=1.00 ; 95 \% \mathrm{CI}$ $0.97-1.03 ; p=0.90)$. Total trauma visits by presenting complaint were 76,981 in cheque weeks and 76,778 in control weeks ( $\mathrm{RR}=1.00 ; 95 \% \mathrm{CI} 0.97-1.03 ; p=0.86)$. A small increase in visits for trauma-related complaints was found on the day of cheque disbursement ( $\mathrm{RR}=1.05 ; 95 \%$ CI 1.01-1.10; $p=0.02$ ), but not on any other day. No significant differences were found for trauma by mechanism of trauma flag. There were no statistical differences in total trauma visits or visits for any specific age group, hospital site, or injury mechanism. In particular, assault/gunshot visits were not significantly increased $(\mathrm{RR}=1.06 ; 95 \% \mathrm{CI}$ $0.99-1.13 ; p=0.08)$. See Appendix 3 and 4 for detailed subgroup analysis.
There were 27,272 ED visits during cheque weeks for mental health and substance-related complaints, versus 25,450 during control weeks ( $\mathrm{RR}=1.07$; $95 \% \mathrm{CI} 1.03-1.11$; $p=0.0006$ ) (Fig. 1). Cheque week was associated with 12.3 (95\% CI 6.2-19.3) excess mental health and substance visits per week compared to control weeks, or approximately 148 excess visits per year. Significantly, there was a $21 \%$ increase in ED visits for substance use ( $\mathrm{RR}=1.21 ; 95 \%$ CI 1.13-1.29, $p<0.0001$ ). Sensitivity analyses revealed that mental health and substance-related visits increased on cheque day and several days thereafter (Fig. 1). We observed no increase in visits on the 2 days immediately prior to cheque disbursement. The increase in mental health and substance-related visits was more pronounced in males $(\mathrm{RR}=1.10 ; 95 \% \mathrm{CI}$ $1.05-1.15 ; p=0.0001)$ than in females $(\mathrm{RR}=1.04 ; 95 \% \mathrm{CI}$ $1.00-1.08 ; p=0.0402)$. These visits increased for all age groups between 17 and 64 years old and at both VGH and $\mathrm{RGH}$, but not at UBCH. See Appendix 5 for detailed subgroup analysis.

\section{Discussion}

We found that visits for mental health and substance use increased significantly in the week following cheque disbursement. This is consistent with previous studies showing increased emergency health service use following cheque day. Significant increases were found at both VGH and $\mathrm{RGH}$, but not at $\mathrm{UBCH}$, which serves mostly university students and residents of higher socioeconomic status (SES). Trauma visits identified using presenting complaints were elevated on cheque disbursement days but not other days. These findings suggest that cheque day-associated harms may not be restricted to mental health and substance use or localized solely in the most concentrated low-income areas. Further research is needed to characterize individuals at risk of cheque day-associated harm in order to better target interventions. This could include prospective studies of outcomes in individuals receiving social assistance.

The increase in substance related visits suggests that the time period immediately following social assistance disbursement may be associated with increased drug or alcohol use. Some literature suggests that social assistance does not cause greater individual substance use but that cheque disbursement affects the timing, not amount, of drug consumption [3]. This phenomenon is closely linked with poverty, as other expenditures (e.g. for food) follow the same cyclic trend for low-income individuals [3]. Alternatively, the social environment of cheque day may act as an environmental cue for drug consumption and drug-related harm [89].

These findings have implications for EDs, pre-hospital medical services, and broader community resources (e.g., 
Fig. 1 Panel 1: ED visits for (1) trauma by presenting complaint, and (2) mental health and substance misuse by presenting complaint. Solid dots indicate point estimate and vertical lines indicate $95 \%$ confidence interval. Red markers indicate relative risks that are significantly increased. Panel 2: ED visits for mental health and substancerelated ED visits. Solid dots indicate point estimate and horizontal lines indicate $95 \%$ confidence interval. Red markers indicate relative risks that are significantly increased
Panel 1: Relative risk of ED visits during cheque weeks compared to control weeks, stratified by day.

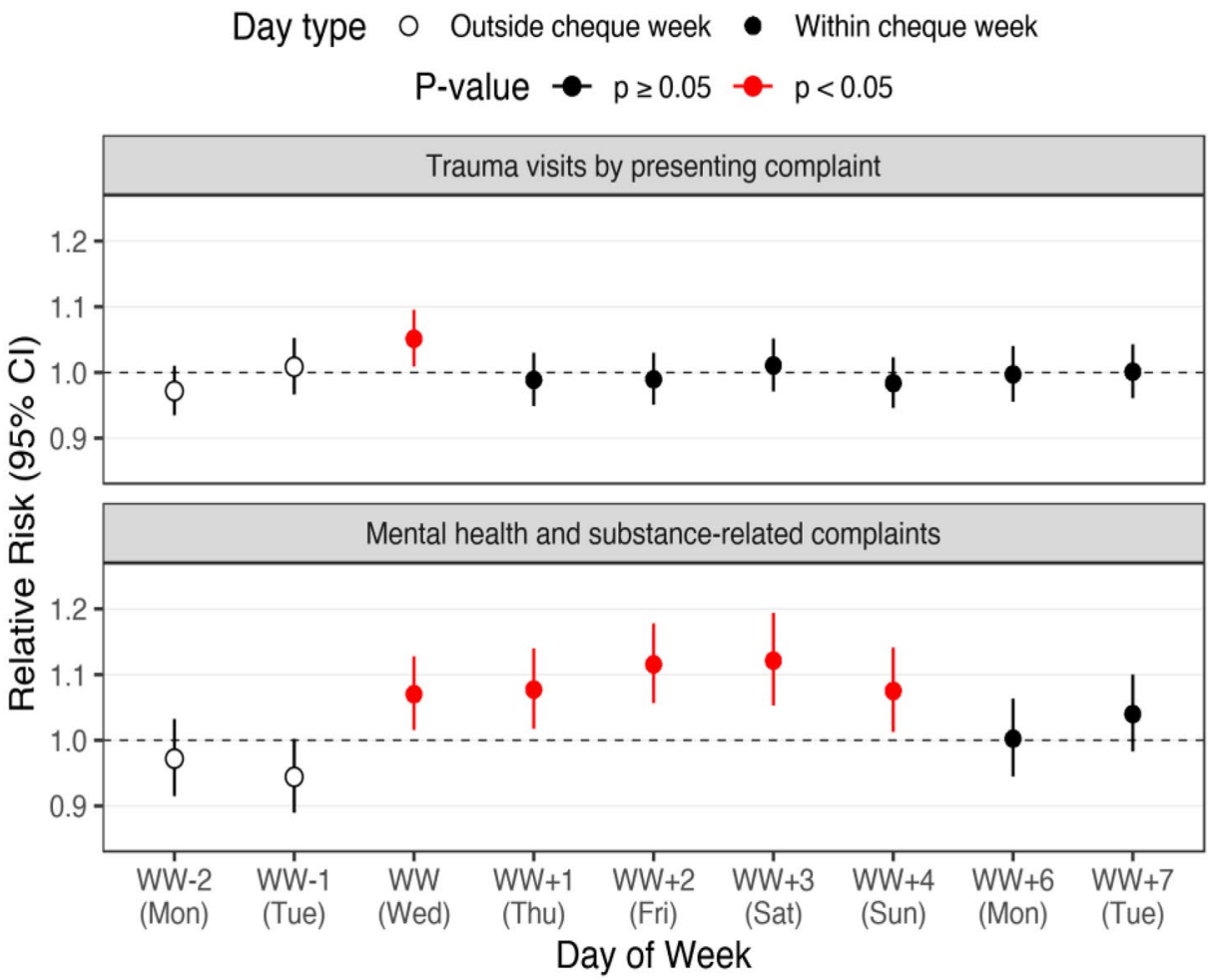

Panel 2: Relative risk of mental health and substance-related ED visits.

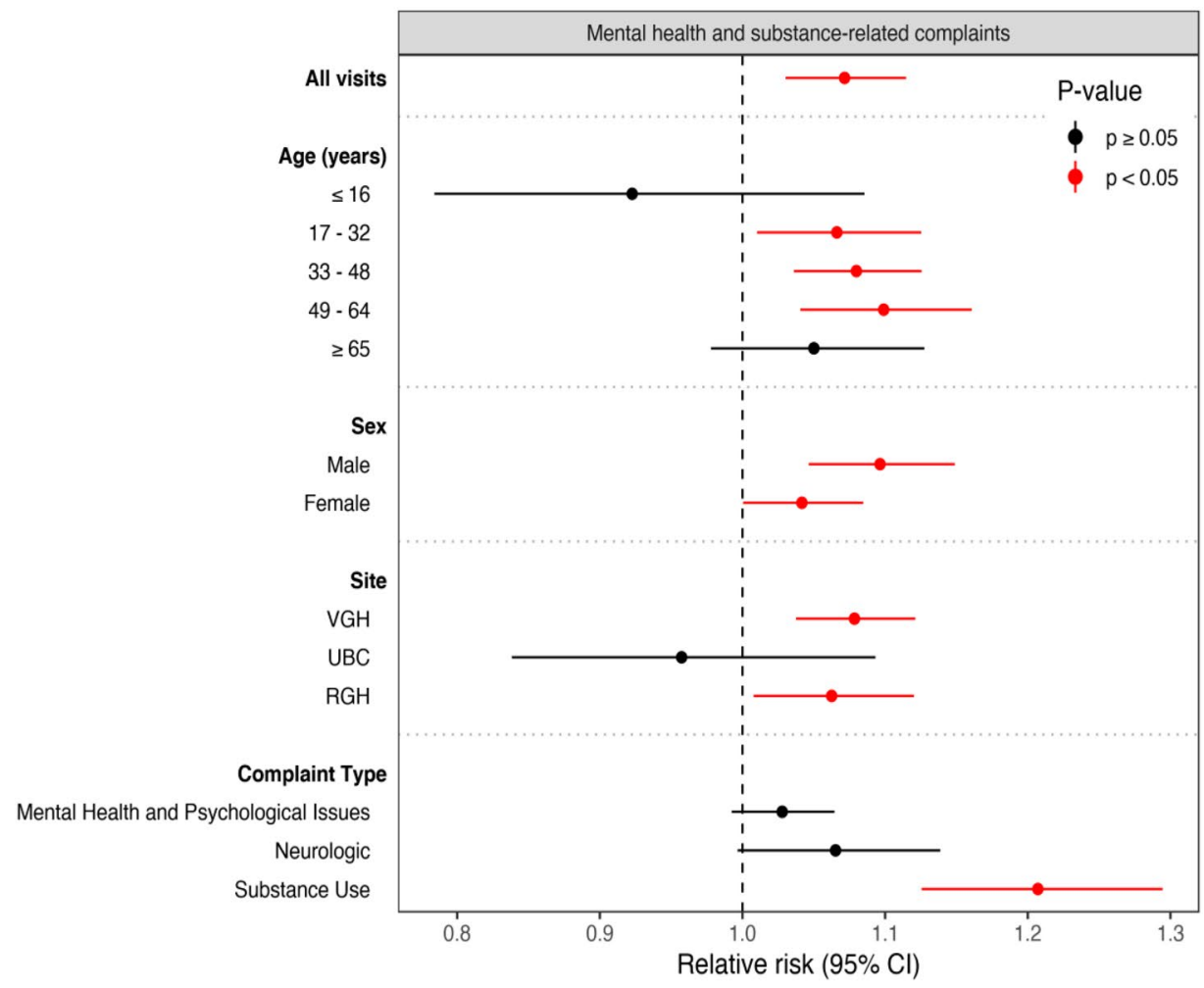


crisis prevention and mental health outreach teams, overdose prevention sites). The increase in ED presentations may inform clinical resource allocation decisions as crowding may affect wait times or length of stay for all patients [10]. Optimal allocation of care providers (e.g., psychiatry or social work) and clinical resources may be hospital or region-dependent and is an area of future research.

Policy-level interventions may also reduce cheque-day harms [3, 5]. Policies such as split or staggered cheque disbursements may decrease drug-related harms by lowering the income disbursed in one payment or reducing community environmental cues. These policy changes should be thoroughly investigated, as they may also cause unintentional consequences such as budgeting concerns for individuals making large payments (e.g., rent or bills) [5].

Finally, research has investigated several mechanisms of managing funds for individuals who receive social assistance and use substances. Generally, assignment of a representative payee (an external source to receive and manage funds) per se has not been found to reduce substance use or improve clinical outcomes such as mental health [3]. However, representative payees may reduce drug-related spending when offered in a voluntary manner with participatory budgeting or in conjunction with treatment and support services at community mental health centres [3].

\section{Strengths and limitations}

Strengths of our study include the use of a broad data set with a large sample size for both trauma ( $n=168,291$ by mechanism of trauma flag, $n=153,759$ by presenting complaint) and mental health and substance-related complaints $(n=52,722)$. Our study extends the generalizability of the cheque effect beyond substance use visits and beyond hospitals that serve the urban core by investigating trauma-associated visits and including Greater Vancouver community hospitals and trauma centres that do not primarily service the urban core. Sensitivity and subgroup analysis provided more detail on the extent of the cheque effect.

Limitations may include an imperfect correspondence of visit data with actual trauma visits due to possible repeat visits, old injuries, or differences in reliability of trauma flag use. Additionally, toxicological analysis data for drug use/overdose were not available in the database. Finally, due to the observational nature of this study, we are unable to determine a causal relationship between social assistance disbursement and ED visits or the mechanism through which an effect may exist.

\section{Conclusion}

We found a significant increase in mental health and substance-related ED visits in the week following social assistance disbursement and an increase in trauma presentations on the day of cheque disbursement. Mental health and substance-related visits were significantly elevated in the first 4 days following cheque disbursement. These findings provide further support to calls for clinical and policy-level changes and support to reduce cheque day-associated harm such as split or staggered payment schedules.

Supplementary Information The online version contains supplementary material available at https://doi.org/10.1007/s43678-021-00115-w.

Author contributions SLB was responsible for study concept and drafting of manuscript. SE was responsible for data analysis. SLB, JRB, SE, JAS, and $\mathrm{HC}$ were responsible for study design and analytic strategy. JRB was responsible for acquisition of data, and SLB, JRB, and SE had full access to all study data. All authors were responsible for critical revision of the manuscript.

Funding None.

\section{Compliance with ethical standards}

Conflict of interest No conflicts of interest.

\section{References}

1. Nelson K. Mechanisms of poverty alleviation: anti-poverty effects of non-means-tested and means-tested benefits in five welfare states. J Eur Soc Policy [Internet]. 2004;14(4):371-90. https:// doi.org/10.1177/0958928704046879.

2. Income Assistance Payment Dates-Province of British Columbia [Internet]. https://www2.gov.bc.ca/gov/content/family-socialsupports/income-assistance/payment-dates. Accessed 18 Jan 2021

3. Rosen MI. The 'check effect' reconsidered. Vol. 106, Addiction. Oxford: Blackwell Publishing Ltd; 2011. p. 1071-7.

4. Verheul G, Singer SM, Christenson JM. Mortality and morbidity associated with the distribution of monthly welfare payments. Vol. 4, academic emergency medicine. Oxford: Blackwell Publishing Ltd; 1997. p. 118-23.

5. British Columbia Centre on Substance Use. The Cheque Day Study community impact statement: perspectives on changing the timing and frequency of income assistance payments [Internet]. Vancouver, BC: British Columbia Centre on Substance Use. May 2019. https://www.bccsu.ca/wp-content/uploads/2019/06/ChequeDay-Study-Community-Impact-Statement.pdf. Accessed 18 Jan 2021

6. Grafstein MDE, Bullard MDMJ, Warren MDD, Unger MDB. Revision of the Canadian Emergency Department Information System (CEDIS) presenting complaint list version 1.1. CJEM J Can Assoc Emerg Physicians [Internet]. 2008;10(2):151-73.

7. R Core Team. R: A language and environment for statistical computing. [Internet]. R Foundation for Statistical Computing. 2018. https://www.r-project.org/. Accessed 1 May 2020 
8. Riddell C, Riddell R. Welfare checks, drug consumption, and health. Vol. 41, Journal of Human Resources. Madison: University of Wisconsin Press; 2006. p. 138.

9. Galea S, Nandi A, Vlahov D. The social epidemiology of substance use. Epidemiol Rev. 2004;26:36-52.

10. McCarthy ML, Zeger SL, Ding R, Levin SR, Desmond JS, Lee J, et al. Crowding delays treatment and lengthens emergency department length of stay, even among high-acuity patients. Ann Emerg Med. 2009;54(4):492-503.e4. 